\title{
To the question of the prospects for the formation of an innovation ecosystem in Kazakhstan
}

\author{
Zulfia Magrupova ${ }^{1}$, Kashamida Tazhibekova ${ }^{1}$, Aigerim Shametova ${ }^{1,}{ }^{,}$, Kulzira Abdraimova ${ }^{1}$, and Kyrmyzy Tursyngaliyeva $^{1}$ \\ ${ }^{1}$ Karaganda technical University, 56, Nazarbayev Avenue, Karaganda, 100003, Republic of Kazakhstan
}

\begin{abstract}
The article presents the results of research on innovation activity based on the analysis of the directions of innovative development of Kazakhstan and suggests a set of measures, the implementation of which will allow building a connected system of measures for the formation of an innovative ecosystem. The main focus is given to improving the efficiency of innovation activities based on an institutional approach, which is aimed at the formation of a stable system of relationships between participants in the innovation cycle, each of which is individually interested in improving competitiveness based on the use of innovations. The formation of an innovation ecosystem also includes the development of two innovation clusters as the basis for the formation of a knowledge-based economy. Based on the analysis provided, we concluded that the organization of innovative infrastructure did not provide the required pace of innovative development of Kazakhstan for a number of reasons. To date, the Republic has successfully implemented state programs that aim to create conditions for the transition to the fourth industrial revolution. The focus on innovative development remains important and mandatory for achieving the goals set out in the program documents.
\end{abstract}

\section{Introduction}

To date, the country is successfully implementing an industrialization Program, and the Third modernization of Kazakhstan has been launched. The development Strategy "Kazakhstan-2050" was adopted, which aims to create conditions for the transition to the fourth industrial revolution. However, we must clearly understand that without relying on science and innovation it is impossible to achieve it. Understanding this important factor contributed to the development of a state program for the development of the National innovation system in Kazakhstan (Programme, 2005-2015). Thus, the focus on innovative development remains important and mandatory for achieving the goals set out in the program documents, which consist in forming an open-type innovation system based on the use of domestic and foreign scientific potential and technologies. The formation of a national innovation system involves the formation of relevant institutions, the role of which in the development of innovation is crucial. In addition, already on the basis of an institutional approach, the task of forming a stable system of relations between all participants in the innovation process is being implemented, taking into account the interests of each.

\section{Problem Statement}

The national scientific and innovation system - as a set of interrelated legislative, structural and functional components, ensures the innovative development of the Republic of Kazakhstan. NIS is considered both as a set of economic entities and as a system of relations between them.

The national innovation system cannot be imported, the Republic of Kazakhstan creates and develops it independently. The main thing is to implement selection of priority scientific and technical directions and the mechanism of their implementation. The model of turning knowledge into innovation is changing. If it was a linear structure in the administrative-command model, then the market model uses a network structure, the elements of which are the academic sector, the applied research cluster, the public sector, the corporate sector, and the main research cluster. The result in the form of new knowledge, ideas, innovations, innovations can be obtained at any stage of the innovation cycle. Market model NIS includes relatively independent sectors of the economy, the relationship between which is determined by market relations, but with the regulatory role of the state.

\section{Research Questions}

The paper analyses the differences between one model of building a NIS (market economy) and another (administrative-command line), which consist of the following.

- In the context of the creation or transformation of new knowledge, a separate economic operator the

*Corresponding author: gsina@mail.ruashametova.74@mail.ru 
subject is focused on the realization of their own interests and values.

- The main thing in the innovation process is the system of relations formed between its participants.

The ongoing processes of regionalization in the economy have created prerequisites for the formation of the regional structure of NIS as an independent subsystem of innovation management. Speaking about RIS, we note that their functional capabilities are individual, since their composition and structure depend on regional specialization, level of education, innovation and economic potentials. The European Commission has defined RIS as "networks of firms forming a local production cluster together with institutional infrastructure" (Russel M. G., 2014201.4). RIS is a multi-level system that includes:

the first level - system-wide, which can be defined as a set of public and private educational and scientific organizations that create and disseminate innovations in the region;

the second level - the branch level, which is a functional subsystem of the regional branch economy;

the third level - institutional, which is considered as a spatially organized subsystem of NIS. Let us denote the material and territorial factors of the allocation of RIS TO an independent NIS subsystem.

Mandatory designation condition RIS as a separate subsystem is the concentration of innovative business structures and institutions within certain territorial boundaries with the appropriate organization of structural links between them and the formation of a system of relationships throughout the research and production cycle. Thus, the spatial concentration of economic entities and the territorial division of labour by region determine the characteristics of RIS and the opportunities for their growth and development. From the point of view of macroeconomics, we can conclude that RIS is a manifestation of the prevailing conditions and factors of production in the region, which determine both internal and external factors for the development of innovation potential. RIS can be represented as a multilevel complex structure in which subsystems can be distinguished with hierarchical links between them (vertical links), and elements combined in blocks (horizontal links) (Rudich S. B., 2017). RIS management presupposes the existence of an object and a subject of management. The object of management is $R \& D$, transfer and commercialization of technologies, the subject of management is economic entities engaged in innovative activities, state and local authorities that regulate the sphere of innovation throughout the scientific and production cycle. And already the interaction of subjects and objects of RIS occurs in the markets for creating innovations and inventions, capital investments and investments, scientific and technical personnel, and innovative infrastructure (Demidov V. A., 2008). The need for the formation of RIS is determined by the field of R\&D and the availability of investment sources of development that require state regulation of innovation activities through the adoption of legislative and regulatory acts and the implementation of managerial functions in this area.

\subsection{Formation of an effective regional innovation system}

To increase the role of regions in the development of innovative business activity, state support for the innovation ecosystem is implemented, which is carried out on the basis of the principle of decentralization. This principle assumes that regions independently form regional innovation policies and finance small and medium-sized business projects. Such policy contributes to the development of inter-regional competition in obtaining budget financing, and on this basis - to the formation of an effective regional innovation system, which includes, on the one hand, an innovative infrastructure, and, on the other hand, a logically linked set of tools for stimulating innovation activity on the part of local authorities. At the same time, M\&E budgets include expenditures on financing the most promising innovation projects and supporting the activities of innovation infrastructure. Central government agencies and development institutions finance the costs of providing methodological and informational support at the expense of Republican budget programs. (GAZINDUSTRY, 2019). The reorientation of the structure of scientific grants and programs for the needs of the state program for industrial and innovative development is directly related to the development of the Law "on the commercialization of the results of scientific and (or) scientific and technical activities", which contains mechanisms for financing the implementation of innovations in production. In 2015, it was approved, and in addition, the Rules for conducting expert reviews of commercialization projects and the rules for financing projects for commercialization of the results of scientific and (or) scientific and technical activities (hereinafter referred to as RSSTA) were adopted. In total, from 2016-2018, in the priority areas of the State program for industrial and innovative development (hereinafter referred to as SPIID) 3 grant financing competitions for commercialization were held. According to the results of competitions in accordance with the decisions of the national tax service, 158 projects in the following areas are financed with an annual budget of 5.4 billion tenge: Agribusiness - 27 projects, Biotechnology - 22 projects; Information technology - 20 projects; Healthcare - 13 projects; food Production - 12 projects; Chemical industry - 12; Construction materials - 10 projects; Energy - 10 projects; machinery and equipment Production - 9 projects; Metallurgy - 8 projects; Ecology - 6 projects; geological exploration - 3 projects; production of other finished products - 3 projects; Nuclear industry - 2 projects; Tourism - 1 project. At the moment, 9 projects have been completed. All projects are aimed at solving strategic problems of the state, while interdisciplinary projects solve the problems of several industries. The end result of each funded project is a new and / or improved product, product or service that is ready to enter the market. By the end of 2019, the following interim results of the implementation of RSSTA commercialization projects were achieved: (Investments, 2019): 
- total income from the sale of innovative products increased from 800 thousand at the beginning of the year to 3.7 billion tenge;

- volume of tax deductions increased from 1 billion to 2.3 billion tenge;

- more than 450 scientists successfully implement businesses based on scientific inventions;

- export volume reached 113.8 million tenge;

- 1,240 jobs were created.

61 RSSTA commercialization projects have reached the production stage. At the end of the three-year sales cycle, by 2021, a socio-economic effect will be achieved in the form of achieving the following indicators: the volume of products sold is more than 15 billion KZT; the amount of tax deductions - more than 5.5 billion tenge; the number of newly created jobs - more than 1,260 ; new types of products - more than 253.

\subsection{Creating an innovative ecosystem}

An innovative ecosystem is formed, which includes the development of two innovation clusters as the basis for the formation of a knowledge-based economy: the Astana business campus of Nazarbayev University and the innovation cluster Park of innovative technologies. For the implementation of specific production projects, the innovative technologies Park attracts local and foreign high-tech companies, it houses research centres and laboratories for joint research projects and development work, as well as their further commercialization. In order to implement this step, the Law of the Republic of Kazakhstan "on the innovation cluster "Park of innovative technologies" dated June 10, 2014 was amended, providing for mechanisms to encourage the attraction of high-tech multinational companies. According to the Strategy for the development of the Innovative cluster "Park of innovative technologies", it is planned to create 5 technology development centres together with TNCs. At the moment, 4 centres have already been created.

In order to continue the development of the innovation ecosystem, within the framework of the Law of the Republic of Kazakhstan dated December 26, 2018 "on amendments and additions to certain legislative acts of the Republic of Kazakhstan on employment", legislative amendments to the Tax code providing for a preferential tax regime came into force in 2019. Startups, including foreign ones, are exempt from paying four main taxes (IPN, CPN, VAT, social tax) in order to reinvest these funds in the development of projects. More than 273 IT companies have already acquired the status of Astana Hub residents. The Technopark also has a special visa and labour regime for foreign employees specialists from other countries can easily obtain a work visa to Kazakhstan for a maximum of 5 years. At the moment, the startup ecosystem created on the basis of Astana Hubincludes more than 273 IT companies registered as participants who have the opportunity to receive tax, labour and visa benefits.

The volume of attracted investments in domestic startups in the company in 2020 amounted to 38 billion tenge, of which 11.7 billion tenge was attracted by startups Astana Hub. To ensure interaction with large domestic enterprises, investors and international partners, the KPMG Digital Village corporate innovation development Center Village, QazAngels business angel club were launched, agreements were reached with Plug \& Play, Amazon Web Services, 500 startups, etc. Investments were attracted from Germany, Singapore, Switzerland, South Korea and the United States. Overall, the Astana Hub has already launched 352 projects (Investments, 2019).

From July 2018 to April 2019, 183 startups completed an incubation program based on the Astana Hub. From February 2018 to May 2020, 138 startups completed the acceleration program. Among them they are convenient round-the-clock Tastamat mail terminals Tastamat for issuing parcels from online stores, the Clockster workplace access control system Clockster and kid security GPS bracelets that allow parents to track their child's location.

A number of innovative startups have already reached the international level. A project at the level of world discovery can also be called AbsCrypt - a program for encrypting large media files, which works much faster than its competitors. Among innovative startups Astana Hub that attracted the attention of investorsBillboard Video. This is a platform for intelligent notification of the population through media boards. Smart billboards display useful information for road users, such as navigation, weather conditions, traffic congestion, and any other relevant messages.

Among the projects is the startup INUI, which builds gaming stadiums in the digital space. By betting on the algorithm, the project solves the problem of fraud in eSports. More than \$3 million was invested in the development of the eSports platform by investors from Switzerland, South Korea and the United States. The beta version of matchmaking is scheduled to launch in early 2020 simultaneously worldwide (BCG, 2019).

In 2017, ACF PIT launched an International acceleration program "Startup company Kazakhstan" for the search, acceleration and financing of startups in order to create a critical mass of high-tech SMEs in the Republic of Kazakhstan. As a result of the advertising campaign conducted in Kazakhstan, the CIS countries and other foreign countries, such as Norway and Poland, about 3,000 applications for participation in the program have been received since 2017 . In order to attract venture co-investments in projects "Startup company Kazakhstan" in 2017, ACF established a joint KazakhAmerican venture investment Fund GVA Alatau Fund. The managing partner is Tech Garden Ventures, LLC (since May 2019). In 2018-2019 (three program streams "Startup company Kazakhstan") GVA Alatau Fund supported 96 innovative start-up projects worth about 990 million tenge in the following areas: Industry 4.0, FINTECH, Smart city, New materials. Having implemented the first stage of creating a professional startup environment through supporting startups at the early stages, the Fund's focus is consistently shifting towards supporting more mature startups, including: portfolio companies, in priority areas of industry 
development in the Republic of Kazakhstan (TSTP "industry 4.0").

The IT quarter in Almaty (created at the expense of private investment) is $100 \%$ full: 4 laboratories with TNCs, more than 50 companies, 40 startup teams are located.

According to the corporate acceleration program, in 2017, 10 companies of the FEZ "PIT", in 2018 - 10 corporations of the Republic of Kazakhstan passed corporate acceleration in Silicon Valley in the USA, in 2019 - more than 10 companies of the Republic of Kazakhstan passed acceleration in South Korea. Since 2020, the main task of the corporate acceleration of ACF Tech Garden is to train and raise awareness of Industry 4.0 technologies using the best international and domestic practices (GAZINDUSTRY, 2019).

\section{Purpose of the Study}

The purpose of the study was to analyze and evaluate the directions of state support for the innovation ecosystem Kazakhstan based on the principle of decentralization

Prior to the adoption of the program of industrial and innovative development of Kazakhstan for 2020-2025, the innovative infrastructure of Kazakhstan included entities created with the participation of state budget funds (Republican, local budgets, funds of organizations with state participation), as well as service development institutions created by the state.

However, this infrastructure did not activate the interaction between its subjects and did not implement the function of providing a full range of services for participants in the innovation process. Organizations of innovative infrastructure did not provide the required pace of innovative development of Kazakhstan for a number of reasons:

- territorial dispersion of regions with innovative potential and insufficient coverage of the innovation infrastructure of the regions;

- need to create an infrastructure to support both sectoral and regional innovation development processes;

- relatively low number of innovative initiatives at the first stage of industrial and innovative development of Kazakhstan, which does not require a large number of innovative infrastructure facilities in one region;

- need to comply with the principle of expediency of expenditures and their compliance with the capabilities of the state budget;

- selection of the most optimal forms of innovation infrastructure organizations to avoid duplication of individual functions;

-actual absence and urgent need to create an information support system for the interaction of all elements and participants of the NIS.

In accordance with the adopted programs of industrial and innovative development of the Republic of Kazakhstan, it is planned to create innovation support centres in each individual region of Kazakhstan on the principle of "one window". They are equipped with the necessary infrastructure and resources to promote innovative projects and assist innovators, as well as have an appropriate mechanism for monitoring and evaluating the results of innovation policy programs.

\section{Research Methods}

Theoretical concepts and methodological developments of domestic and foreign scientists on the development of innovative ecosystems served as the theoretical basis for scientific research, and in addition, general scientific methods were used, including the system approach, network theory, expert assessment method, classification of species, comparison method, quantitative analysis methods, and some others.

Periodical, statistical, analytical and translated literature on the research area was used as information resources.

\section{Findings}

In the modern world, the level of development of the state depends on achievements in the field of innovation. Innovations should be characterized by novelty, applicability in any field of human activity, the ability to quickly implement in the market, and the ability to bring economic and other types of effect. In Kazakhstan, there are prerequisites for reorienting the state's priorities to support innovation. For successful and rapid transfer of new scientific knowledge to the economy, it is necessary to create a modern effective national innovation system and achieve a high national innovation capacity of society, following the example of economically developed countries. For the formation of an innovative economy of the country, the following is required: creation of innovative technologies; a set of systematic measures that ensure a rapid change of marketable products that are ahead of competitors. It includes the implementation of the innovative principle: "everything that works is already outdated"; priority solution to the problem of high quality of products; transition to" innovative" education, with the development of creative abilities, the formation of a national innovative mentality, innovative culture.

Public financing and regulation of innovation processes play an important role for the effective development of innovation activities. The innovation process should be funded from various sources. State regulation is a prerequisite for the successful development of innovation activities. It is necessary to carefully coordinate the activities of all participants in the innovation process, using the levers of the market economy: it is necessary to lower the credit rates of banks, attract financial resources from the private sector, involve more enterprises and organizations in the innovation process, thereby reducing the economic risk of innovation, expanding the potential opportunities for innovative development of the country's economy. 


\section{Conclusion}

The loan Agreement between the Republic of Kazakhstan and the World Bank on the implementation of the joint project "Stimulating productive innovations" (hereinafter referred to as the Project) was signed and ratified. Pursuant to the order of the Deputy Prime Minister of the Republic of Kazakhstan dated October 31, 2019 No. 17-12 / 2533, the ICRIAP of the Republic of Kazakhstan was designated as the project administrator, and on the basis of the act of acceptance and transfer in 2020, it was transferred to the ICRIAP of the Republic of Kazakhstan. The change of administrative subordination will allow implementing a number of measures:

1 PR. company concerns the need for digitalization of industrial enterprises by the example of best practices;

2. promotion of the Smart Industry Management Platform (SIMP) among it companies and industrial enterprises;

3.informing industrial enterprises about Industry 4.0 technologies;

4.conducting educational events on Industry 4.0 technologies;

5. acceleration of mature solutions for industry;

6. promotion of IT companies participating in the Smart Industry Management Platform (SIMP). To this end, the center for technological development (competencies) in the industrial sphere (MMC) of the Republic of Kazakhstan is being created. ACF is actively negotiating with TNCs (McKinsey\&Co, Siemens, Honeywell, Parallel, etc.).

This, in turn, will allow us to optimize the work on further attracting high-tech companies, registering a joint venture, implementing production projects and startups, as well as supporting more mature projects, including portfolio companies

\section{References}

1. V. A. Demidov, N. N. Lebedeva, O. S. Oleinik Regional innovation system: potential and development trends (Publishing house Volga state University, Russia, 2008).

2. Investment as a key driver of Kazakhstan's economic growth: new enterprises, advanced technologies and job creation, Review, Retrieved from:

/https://primeminister.kz/ru/news/reviews/investic ii-kak-klyuchevoy-drayver-rosta-kazahstanskoyekonomiki-novye-predpriyatiya-peredovyetehnologii-i-sozdanie-rabochih-mest (2019)

3. M.G. Russel et al. Business Angels and Investment Organizations as Networked Cocreators of the Finnish Innovation Ecosystem Triple Helix IX International Conference "Silicon Valley: Global Model or Unique Anomaly? (2011)

4. GAZINDUSTRY. New industrial policy of SPIID 3.0 / JSC "Kazakhstan centre for industry and export", Retrieved from: https://almaty.atameken.kz/uploads/content/files/ $\% \mathrm{D} 0 \% 9 \mathrm{~F} \% \mathrm{D} 1 \% 80 \% \mathrm{D} 0 \% \mathrm{~B} 5 \% \mathrm{D} 0 \% \mathrm{~B} 7 \% \mathrm{D} 0 \% \mathrm{~B} 5$ $\% \mathrm{D} 0 \% \mathrm{BD} \% \mathrm{D} 1 \% 82 \% \mathrm{D} 0 \% \mathrm{~B} 0 \% \mathrm{D} 1 \% 86 \% \mathrm{D} 0 \% \mathrm{~B}$ 8\%D1\%8F\%20QAZINDUSTRY\%20for\%20busi nesses.pdf. (2019)

5. BCG. JSC "Samruk-Kazyna". Magro-economic prospects of Kazakhstan and new investment horizons in digitalization. Retrieved from: https://sk.kz/upload/iblock/c8c/c8c46093ecd0338 3b2294ab438a7c083.pdf

6. S. B. Rudich Ekonomicheskie nauki, 41, (2017)

7. Program on formation and development of the national innovation system of the Republic of Kazakhstan for 2005-2015 Retrieved from: http://adilet.zan.kz/rus/docs/P050000387_\#1. 